\title{
Construction and assembly works planning: optimization or search for solutions
}

\author{
E. Gusev ${ }^{1, *}$ \\ ${ }^{1}$ South Ural State University, Chelyabinsk, Russia
}

\begin{abstract}
The article analyzes the instability causes of construction and assembly works (CAW) schedules which leads to the construction works and logistics instability. The "nature" of multi-variant management solutions is considered. The contradiction of requirements to the basic organizational and technological model (OTM) to solve scheduling problems of CAW and construction works is revealed. The basic "an object construction technology model" as "an object techno-logical dependencies models" is considered. A new approach is proposed to solve the problem of CAW scheduling, which includes two-step managerial decisions development at the CAW planning stage and construction works organization stage. At the first stage, the problem is reduced to finding a solution (and not to determining an optimal variant). At the second stage, the problem is solved through optimization.
\end{abstract}

\section{Introduction}

The period of 1940-70th saw a strong penetration into the economy and managing the economic-mathematical modeling (EMM) and a new direction in mathematics optimization problems solving. During this period, mathematicians made a significant progress in modeling various sectors of the economy management, including construction, developed methods for optimizing management decisions, methods for decision making under the uncertainty and incomplete information conditions, etc. Anyway, a scientific research or scientific publication without economic and mathematical modeling and optimization was difficult to imagine $[1,2,3]$.

Such optimization techniques as "Calibration" and "Smoothing" are widely used in the construction industry. To re-solve economic and administrative problems, methods of linear and dynamic programming, simulation modelling, multi-criteria optimization and many others are applied. This period can be labelled as an euphoria of universal optimization in economy and economy management.

However, in 1970, in the book "Mathematics puts the experiment" N. Moiseev questioned the optimization method in solving economic and management problems. The quintessence of the book is the phrase emphasizing "the significance" for using optimization methods: "and rolled the "wheel" of optimization along one way, and the economy - along the other one" [4].

Many systems and subsystems of management in construction were developed and a large number of scientific articles and various publications were issued [5, $6,7,8,9,10,11,12,13,14]$. In the former Soviet Union, the most popular and completed, in the opinion of the author, was the system of "A-Plan", which was developed based on the construction trust "Tallinstroy", headed by L. Golub [15]. This system was awarded with a gold medal of the USSR Economic Achievements Exhibition. However, after about ten years of implementation and operation, the main ideologist of the system admitted that its results were more frustrating than positive.

In any case, various objectives analysis for construction and assembly works (CAW) scheduling and their practical application shows that the optimization plans do not lead to the desired result, which was expected by the developers and users. To evaluate the causes of inefficiency in solving CAW scheduling problems, the scheme (Fig. 1) is to be examined.

\section{The basic sequence of a balanced caw schedule development}

As a basis for CAW planning (Stage 1), organizational and technological models (OTM) in the form of linear[16], network diagrams, and sequence diagrams are used. In this case, the selected model can be optimized or nonoptimized. Therefore, the optimal criterion in the scheme is highlighted with a dotted rectangle.

The second stage of the "Scheduling" module is solved only through optimization.

Management theory considers any process of managing an entity as a uniformity for objectives selection, their achievement programs (or plans) and implementation mechanisms that compensate for all kinds of interference. With regard to a construction company, developing the objectives that determine the stability is to make planning decisions (the system of technical and economic indicators), which would ensure its viability. In fact, the planning decisions are a doctrine that is

\footnotetext{
Corresponding author: gusevev@susu.ru
} 


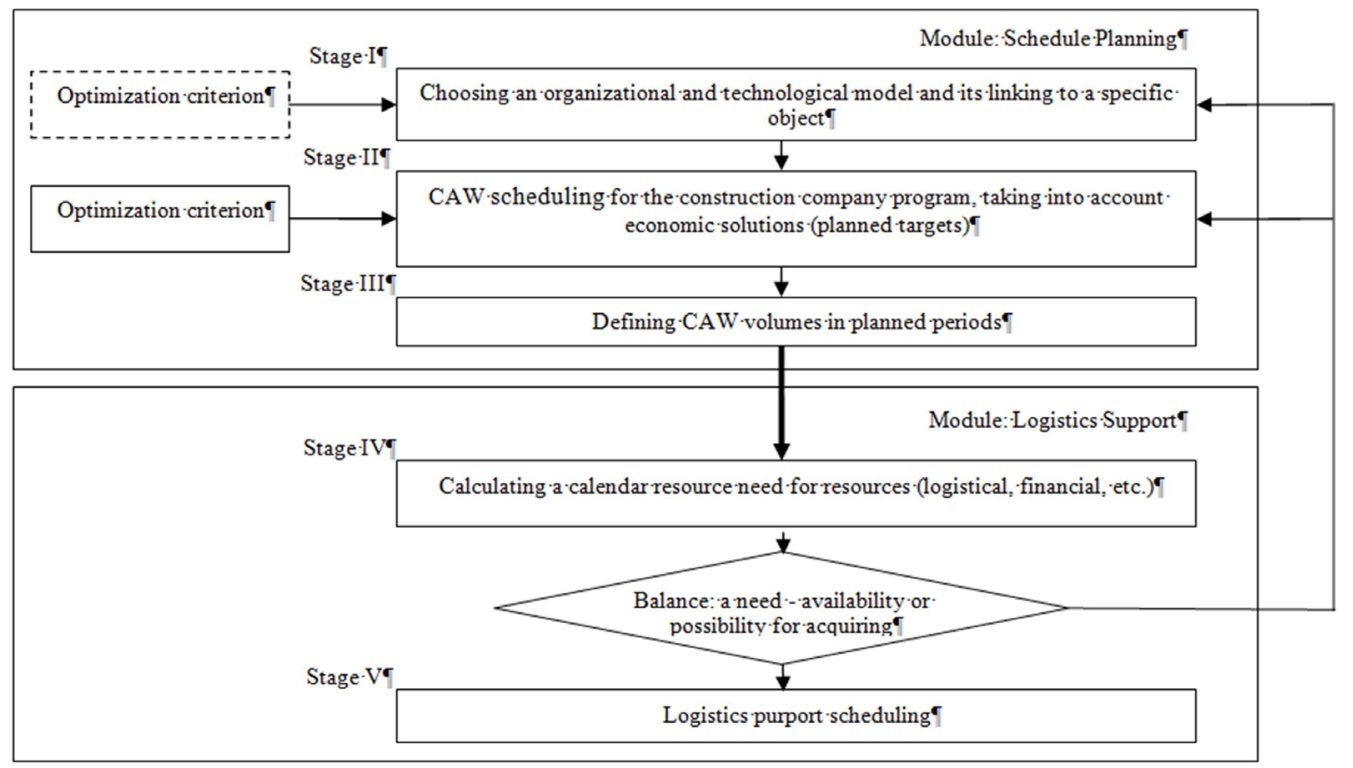

Fig. 1. The basic sequence of a balanced CAW schedule development for a construction enterprise.

determined by external conditions, but it is not external to the construction company itself. Changes of external conditions entail the mandatory change of the doctrine [4].

For developing a CAW schedule, the first and second stages of the "Scheduling" module are assumed to be multi-variable in nature and, therefore, the solution of the problems at these stages requires optimization.

The solution of optimization problems is known to be related to a multiple choice of possible ways to achieve the targets (doctrine), followed by finding a extremum.

For CAW scheduling, such a multiple choice is "provided" in two ways:

1) the top managers of construction companies are considered to have a variety of options for CAW time planning;

2) the number of restrictions, requirements and conditions are purposefully reduced to facilitate the economical and mathematical model and reduce the complexity of problem solving [17,18].

The first way involves obtaining an optimal plan for project (s) construction, that is a construction schedule, and this schedule should "adapt" the entire infrastructure (finance, logistics, human resources, etc.). Operating a well-known industrial installation "Accord" has shown the futility of this approach.

As to the second way, let's consider the diagram shown in Fig. 2. Point A is the level of the current conditions of a construction company (the socioeconomic system) and point $\mathrm{B}$ is technical and economic parameters (doctrine) to be achieved in a given (fixed) period.

Construction companies operate under a variety of restrictions, terms and conditions. Therefore, the increase in-various limitations in the process of CAW scheduling leads to a decrease in the area of management decision-making. There may be three options (Fig. 2).

Option 1: The combination of various types of restrictions leads to inability to achieve the planned technical and economic indicators (TEI). In this case, the decision-maker (DM) has to make a difficult choice:

a) to adjust TEI to the worst compared to a planned one;

b) to take extra costs to ensure the planned TEI achievement.

Option 2. The author does not exclude the possibility of an area formation for management decisions making during CAW scheduling, that is an area of several ways of achieving the set goals (planned TEI). In this case, this problem is solved using the optimization methods. It is imperative to know these ways instead of creating multiple choice by artificial reduction of input data quantity, purposeful reduction of constraints quantity, as input of "additional" constraints into economical and mathematical model allegedly "leads to the optimization effect partial loss" [17, 18].

Option 3. A construction company is set under various rigid constraints - financial, capacity, logistical, time, technological, organizational, etc. This set of constraints ultimately determines the CAW scheduling specific parameters and distributing the amount of construction works in time. Current practice analysis shows that the task of a construction company manager (management) is not to choose the best option on a certain criterion, but to find a way leading to the planned decisions (assignments, TEI) implementation, to anticipate the factors that may affect the program implementation, and take them into account at the planning stage.

Let's consider another aspect. The scheme in Fig. 1 is essentially the second component of management theory - developing a program (plan) for goals achievement.

In the scheme in Fig. 1 a special attention should be paid to the next important point. Among all the CAW scheduling stages, it is only at the fifth stage in the module "logistics support" when the documents developed have legal force (contracts with different enterprises and organizations) are developed.

The optimal CAW scheduled plan developed and balanced with the logistics provision is a design 


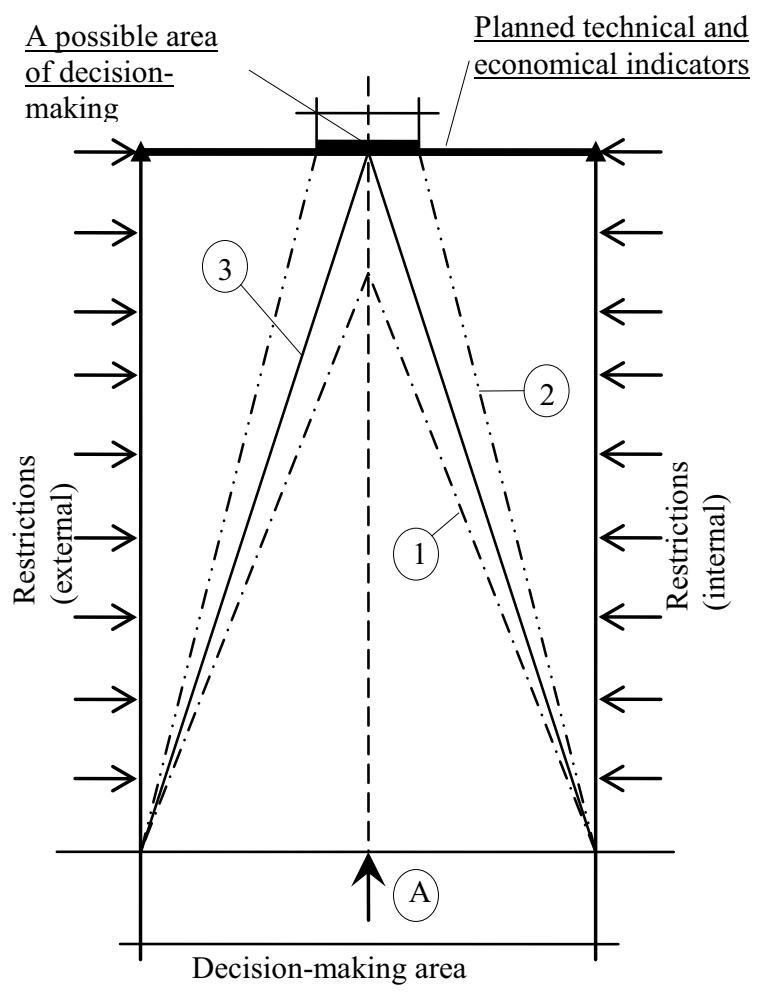

Fig. 2. Schematic diagram of the dependence of the decisionmaking (multi-variant) area on the number of restrictions considered.

decision. During the plan implementation (the third component of the management theory), as a result of various external and internal factors, it requires a corresponding correction (adaptation). But, the logistics support plan "works" for the initial schedule of construction, and changes in contractual obligations lead to costs rise, increased construction costs and the imbalance of administrative decisions.

\section{The structure and interrelation of the schedule elements}

The reason for this discrepancy is the following. The planned construction schedule of an entity (complex of entities) is a source of information for solving many logistical problems. Therefore, the requirements to the information must be strictly implemented - it should be stable, unchangeable. At the same time, construction schedules are the organizational and technological models, primarily reflecting organizational solutions and technological stages of inter-related works. As a result, opposite requirements for the schedule are presented, both objectively and dialectically legitimate. On the one hand, the schedules must be resistant to various disturbing influences, stable, objective, since the information obtained from them is used to solve the exact calculation problems of works distribution in time, logistics, the construction company potential balances and planned indicators checking, the subcontractors work, etc.

On the other hand, the models are required to be easily adjusted. This requirement belongs to the general
CAW schedule

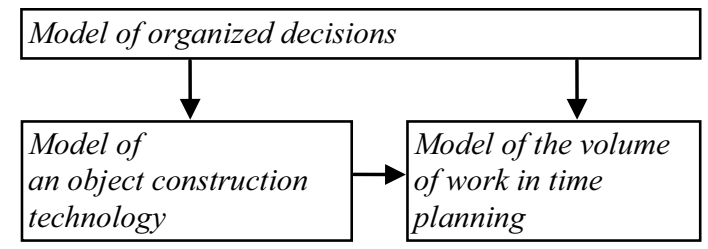

Fig. 3. The structure and interrelation of the schedule elements.

\section{Schedule}

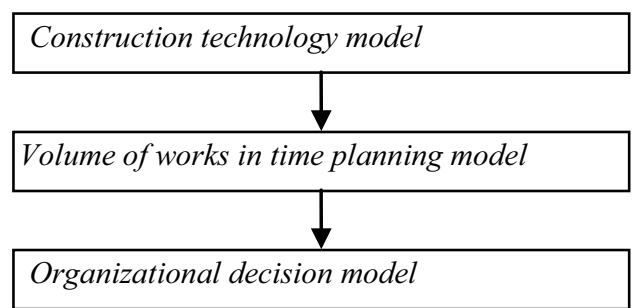

Fig. 4. New structural model interconnection of the BAW scheduling.

management theory, as all the external and internal influencing factors cannot be taken into account in making management decisions.

The revealed objective contradiction of requirements to the schedule allows to rethink its "internal" content. To fully understand the causes of CAW schedules instability the concept of "three models" should be considered [19]. Its essence lies in the fact that the schedule cannot be considered as a homogeneous "monolith", described in time, volume and resources (such as power) parameters. It can be represented as a synthesis of three interrelated models. These models reflect an object construction technology, construction organization and the volume of work in time planning (distribution), which allows to obtain a set of CAW scheduling parameters (Fig. 3).

The decision organization model includes a wide range of activities related to the building production organization. The main objective of the model is to define time parameters.

The work volume planning model generates a decision on the objects of working time distribution. The main goal of this model is to develop solutions that determine what kinds of work, to what extent and on what items should be made in each specific period of time taking into account various types of restrictions and requirements.

Construction technology model is rather weakly expressed in the schedule. The main goal of this model is the buildings and structures designing technology.

According to the scheduling rules for construction and assembly works (BAW), needed for the construction project, the organizational model holds the priority position in this interconnection. After organizational decisions, based on the technological 
sequence of interrelated works, the volume of work in time is calculated.

With such structural interconnection of "internal" models planning the volume of work is like "a secondary stage" that is after the time parameters modelling we determine those volumes of works for the project that should be done in one or another planning period.

Considering these models in terms of their stability and resistance to various factors, one can draw the following conclusion.

The construction technology is quite limited in choice. Basically, there are two technological schemes of building construction: from the foundation to the roof; from the roof to the foundation. Therefore, the technology model is the most stable (here we assume that the technological stages of interrelated works is a component part in a construction technology) [20].

The organizational model is the most unstable as under the influence of various factors during the construction period, organizational decisions are changing repeatedly. This leads to some changes in the planning model. Organizational decisions instability is objective and this leads to instability in the volume of work in the logistical sup-port. Generated "internal «interconnection in the schedule has leads to a shift in understanding the scheduling. The purpose is not to allocate resources, such as power, for the works and facilities for the construction organization immediately but to determine the volume of work which lead to achieving engineering-and-economical performance taking into account construction organization capacity, various restrictions and technological requirements. For this approach construction technology model should play the major role as a base model for the management decisions development concerning BAW planning and construction organization (see Fig. 4).

Taking into consideration such interconnection, organizational decisions are made only when volumes of work and the conditions at the construction site are known. In this case, the volume parameters are more stable and less affected by various factors. This approach allows to divide scheduling BAW task into two stages. At the first stage the types and volumes of work to fulfill the planned-economic tasks (decisions) for a planning period are determined, taking into account the output, various resources endowments, construction technology requirements, etc. The obtained results are additional restrictions on the second stage, where organizational decisions are specified.

\section{A project technological dependencies model}

In order to implement a two-stage scheduling BAW, a basic model should be made based on the construction technology model which is the most stable to the influence of various factors.

Currently the term "construction technology" is associated with the manufacturing stages of works in the project and their interconnection. However, there is no quantitative relationship between interrelated works.
The term "construction technology" can be defined as follows: "it is a qualitative and qualitative assessment for the technological links between the works determining the work planning possibility and industrial organization depending on the results of the previous ones". In this case, the point of the construction technology modelling is to establish technological links between various works and to determine a minimum volume of the previous works that give the possibility to plan a technologically interconnected volume of the following stage.

Such model describing the technological links between works stages and their quantitative assessment in the be-ginning and after their completion of work is designed and presented in Fig. $5\left(T_{\text {dir }}-\right.$ directory (normative, contractual) duration of the objection struction; $t_{j}-$ duration of time area; $t_{j h} ; t_{j o}-$ technologically possible beginning and completion of work; $t_{j+1, j}^{H}, t_{j+1, j}^{o}-$ minimum technological delays during the beginning and completion of the following work $(j+1)$ from the point of the beginning and completion of the previous work $(j) ; t_{j}^{k p}-$ criticality point after which execution of the volume of work demands maximum intensity and can lead to disruption of work $T_{\text {dir }}$ ). It is important that there are no organizational decisions when calculating quantitative assessments. This increases the model stability when planning BAW and construction organization. As technological dependences for the initial and final works determine the technological stages of the project works, we will term it as a project technological dependencies model (OTDM).

OTDM calculation is reduced to time assessments for technological dependencies for the initial (not earlier than the initial) and the final (not earlier than the final) works; time area for each stage (as opposed to the duration of the work according to OTM); criticality points of stages. "Not earlier than the initial one" means that follow-up work $(j+1)$ cannot start technologically if functional minimum volume of work is not done (planned) on the preceding $\mathrm{j}$; "not earlier than the final one" means that follow-up work $(j+1)$ technologically may not end earlier if the minimum volume of work technologically essential after the previous work (j) is not be done (planned).

The first stage of scheduling BAW is connected to the volume of work time distribution (for the planning period). Based on the task set to the building organization -fulfillment of planned technical and economic tasks (decisions) - work method statement which should be balanced with planned tasks (decisions) and logistic provision plan are to be developed.

The construction company does the projects within the tough limits due to many different restrictions of social, organizational, technological, technical, logistical nature and other requirements [21]. Such variety of restrictions and requirements questions the fact that the construction company leaders have a number of decisions about scheduling BAW. The author in his further reasoning is based on the following hypothesis: "Taking into account sufficiently large number of 


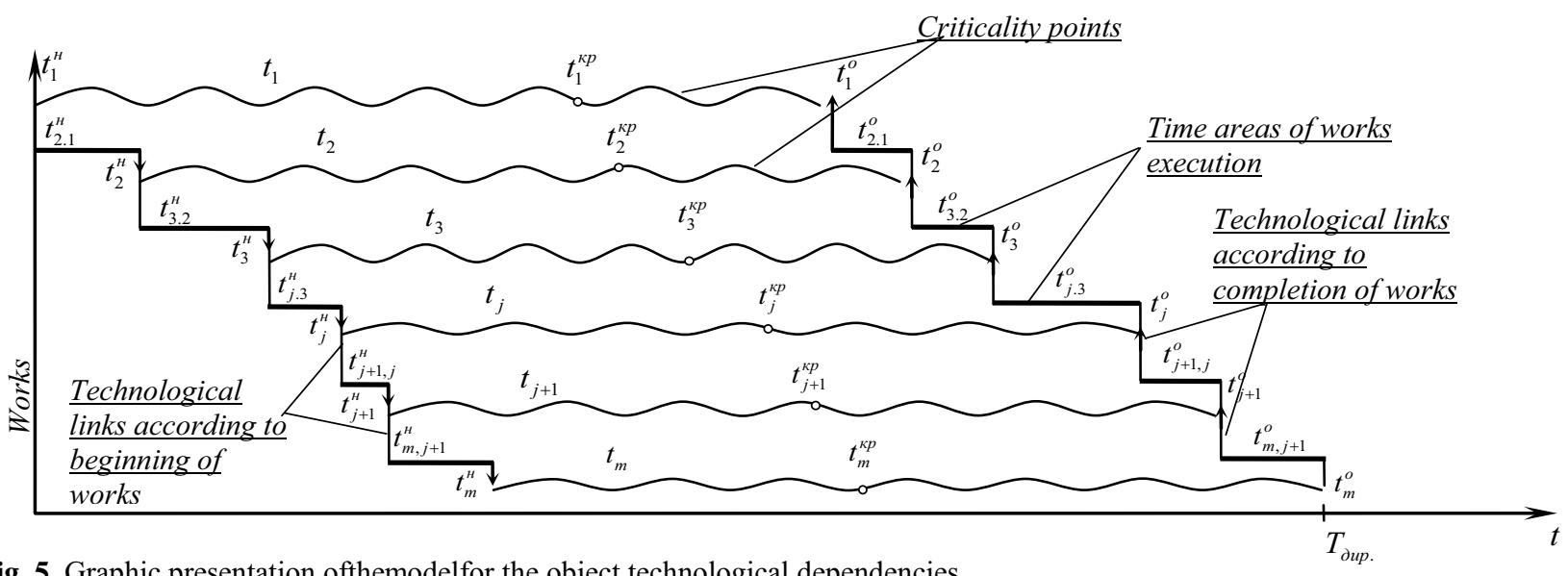

Fig. 5. Graphic presentation ofthemodelfor the object technological dependencies.

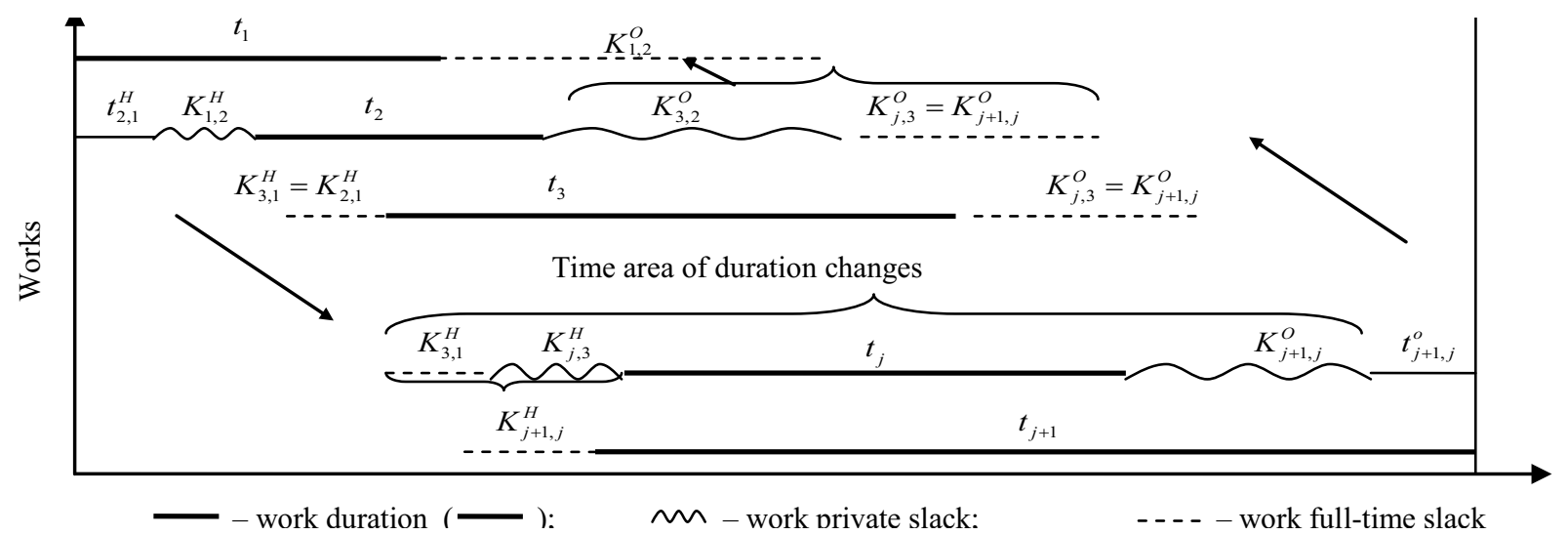

Fig. 6. Line graph with slacks by the beginning and completion of works.

restrictions, the task comes to finding ways to achieve the goal (scheduled TEI), or to the only one alternative". Therefore, it is necessary not to reduce the number of restrictions but gradually, in the course of evaluation to fill with them, thereby the reliability and stability of the results are increased. Therefore, the solution of this problem is aimed not to choose the best option according to the specified criterion but to find the way (or ways) to achieve goals under the given conditions that is the problem content is to find such a set of project works in quantity and financial terms which ensures fulfilling the planned economic tasks (decisions) by a construction company. The solution is to find a set of work volumes which construction company should perform in each planning period of the planning year to ensure their own viability.

The task has a twofold purpose. On the one hand, the task is to make a set of works of the planned technical and economic indicators, on the other hand, the task is to check the validity of these indicators that is whether the construction process can ensure these indicators taking into account various restrictions and requirements. Therefore, the process of solving the problem is closely linked to the work of planning, construction process, logistic and other functional de-apartments in a construction company.

The task of the current (operational) scheduling BAW for the construction company at the first stage which is based on the unconditional fulfillment of the planned tasks (decisions), and technical and economic indicators (set by appropriate planning departments) can be defined as follows: the production program of a construction company is formed from «n» projects. Planning tasks are defined with the breakdown by performers and customers.

It is required to determine types and volume of work for each scheduled period of the year $\left(V_{i, j, \tau}^{n \pi}\right)$ which ensures the annual goal achievement (with breakdown by planning periods) by a construction company.

During the time distribution of the works volume in addition to the goals, a number of requirements and conditions related to the construction manufacturing, maintenance by labor, material, technical and financial resources, labor conditions, and so on should be taken into account.

The second stage is connected with the development of organizational decisions. First of all it is the determination of intensity, interchangeability, duration of work, the beginning and the end of each construction process in the time area, combining the technologically-related works, etc. But the basis for all the organizational issues is the labor resources allocation of the project and types of works because only the accepted allocation determines other organizational decisions to a large extent. Organizational decisions development is directly related to optimization.

In scheduling there are numerous criteria, and the criterion system. One of the most complete reviews of the methods and criteria for the construction 
production organization is A.A. Gusakov's review [20].

When calculating the construction object schedule, further restrictions must be considered: the works time area, certain volumes of works distribution for time periods, the availability of the critical points of the initial stage, quantitative and qualitative parameters of technological dependencies, etc. It is important that the distribution of BAW volumes by time periods may be irregular. And this leads to calculating the time schedule for each planning period. The obtained construction schedule (time parameters) must be within the boundaries of the work time areas, certain OTDM (Fig. 6). A special feature of this calculating a line graph method is to identify private and full-time slacks.

Currently considered approach to the scheduling BAW development is implemented in the form of software product OTDM and problems statement at the first and second stages.

The work was supported by Act 211 Government of the Russian Federation, contract № 02.A03.21.0011.

\section{References}

1. K. Aksyonov, E. Bykov, O. Aksyonova, Proc. Intelligent Systems Modelling \& Simulation (ISMS), 310-314 (2013)

2. K. Kim, J. Walewski, Y. Cho, J. Manage. Eng., (2015). 10.1061/(ASCE)ME.1943-5479.0000374, 04015038 .

3. U. Klanšek, J. Constr. Eng. Manage., (2015). 10.1061/(ASCE)CO.1943-7862.0001074, 04015088 .

4. N.N. Moiseev, Mathematics set up an experiment (Nauka, Moscow, 1970)

5. G. Ma, A. Wang, N. Li, L. Gu, Q. Ai, Journal of Construction Engineering and Management, 140(12), 04014055 (2014)

6. J.T. O’Connor, W.J. O’Brien, J.Ouk Choi, Practice Periodical on Structural Design and Construction, 04015014 (2015)
7. E.H. Oh, N. Naderpa-jouh, M. Hastak, S.Gokhale, Journal of Construction Engineering and Management, 142(2), 04015067 (2015)

8. M.F.F. Siu, M. Lu, S.AbouRizk, Journal of Construction Engineering and Management, 142(1), 04015048 (2015)

9. Y. Gajpal, A. Elazouni, Construction Management and Economics, 33(7), 531-553 (2015)

10. A. Francis, Procedia Engineering, 123, 162-168 (2015)

11. T. Horenburg, W.A.Günthner, Computing in Civil Engineering, (2013)

12. S.M. Chen, P.H. Chen, L.M. Chang, Automation in construction, 21, 99-113 (2012)

13. O. Salem, S. Mohanty, Journal of Construction Engineering and Management, 134(7), 501-508 (2008)

14. A. Baldwin, D. Bordoli, Handbook for construction planning and scheduling (John Wiley \& Sons, 2014)

15. L.G. Golub, E.N. Lyashchenko, MIS of $a$ construction trust (Stroyizdat, Moscow, 1976)

16. V.I. Varapaev, Models and methods of scheduling in construction management automated systems (Stroyizdat, Moscow, 1975)

17. K.A. Antanavichyus, Multilevel stochastic simulation of industry splanned solutions (Vilnius, Mokslas, 1977)

18. K.A. Antanavichyus, Designing and optimization in construction management (Stroyizdat, Moscow, 1979)

19. E.V. Gusev, Technological designing and balanced planning of $B A W$ (RIK "Redaktor", Chelyabinsk, 1990)

20. A.A. Gusakov, Organizational and technological reliability of construction operations (Stroyizdat, Moscow, 1974)

21. P. Lorterapong, M. Ussavadilokrit, Journal of Construction Engineering and Management, 139(4), 414-422 (2012) 